\title{
Energy-Efficient Buildings, a step towards Sustainability in Pakistan
}

\author{
H. USMAN \\ University of Debrecen, Faculty of Engineering Management \& Enterprise, Ranahashir99@gmail.com
}

Abstract. With every passing year, energy consumption in the world is increasing drastically. Most of the energy comes from fossil fuels which are also depleting in a fast manner. Buildings consume a significant amount of energy all over the world and the demand for energy is also increasing unremittingly in buildings. Developed countries are taking profound measures in order to make buildings energy efficient and sustainable by achieving nearly zero energy stage. Pakistan is facing a serious energy crisis from the past few decades. The building sector in Pakistan deserves special attention in this regard since the energy consumption in buildings in Pakistan is feverishly high. Many types of research have been carried out in Pakistan by the United Nations and Energy Department of Pakistan in order to devise applicable methods that not only provide thermal comfort to the occupants but also make a building energy efficient. Renewable energy also plays an important role in compensating building energy demands. It is easy to achieve nearly zero energy state in a good energy efficient building if it is coupled with renewable energy sources then it will make it self-sufficient in energy demand. A survey is also carried out to determine the thermal comfort of the occupants in different types of areas. Also, solar energy analysis is also taken into account to highlight the solar power potential in Pakistan. Several recommendations have also been suggested to implement energy efficiency measures in Pakistan.

\section{Introduction}

The world is urbanizing rapidly. More and more people are moving towards cities. A study indicates that in $1990,13 \%$ of the total global population lived in cities and now it has crossed $50 \%$ of the total global population residing in urban areas [1]. This exorbitant growth of the population in cities is also linked with high resource utilization and carbon footprint. A report by WWF suggests that cities are mainly responsible for more than $70 \%$ of carbon dioxide emissions worldwide [2]. It is a common perspective that transportation category has a huge role in energy consumption. But it is a surprising fact that buildings consume even more than the energy consumed by automobiles or other means of transportation and it even stands at the second position in global energy consumption. International Energy Agency (IEA) published in their Energy Technology Perspective 2017's report that the energy consumption by transport is $28 \%$ whereas the share for buildings is $30 \%$ which is only $1 \%$ less from industry which consumes $31 \%$ of the whole global energy and stands 1 st in 2015 [3].

Moreover, the energy demand is increasing rapidly due to an increase in population and economic growth, mostly in large developing countries, which will be responsible for a $90 \%$ hike in energy demand by 2030 [4]. 
Since buildings consume a really large proportion of energy in the world and the developed countries are striving to save energy and make their buildings more energy efficient and sustainable. Many initiatives have been put in place already by the developed world. For instance, European Union has initiated a forum known as The Concerted Action EPBD (Energy Performance of Building Directive) and they are trying to make every new building nearly zero-energy building by the end of 2020 [5]. Nearly zero-energy buildings are those buildings that have a very high energy performance and there is minimum energy demand or almost zero energy is required that should be covered by renewable means [6]. The passive house is also a prominent platform that encourages people to make their houses energy efficient by saving energy consumption and granting thermal comfort [7].

As far as Pakistan is concerned, we are really behind in the energy optimization of buildings. In fact, it is not considered as important as it must be. It is a common observation that people just get their homes built from masons who do not care about energy efficiency, insulation, and thermal comfort. Generally, there are only a few housing schemes in some cities where everything is well planned and designed but in the large portion of the cities, there are irregular, random and unregulated construction [8]. Housing schemes like Defence Housing Authority (DHA), Bahria Town, EME society, etc. are well planned and designed but generally, building energy efficiency is not stressed enough there as well.

Reducing energy consumption is extremely important to Pakistan since Pakistan is striving against an issue of imbalance between demand and supply. Pakistan has the worst energy crisis from the last few decades since energy production is not able to meet the energy demand of the country. The electricity supply system is really unreliable and old, therefore, the distribution and transmission losses are much higher than other Asian countries [9].

A report shows that the consumption from 1980 to 2013 has been increased drastically worldwide as compared to the production (Fig. 1) [10].

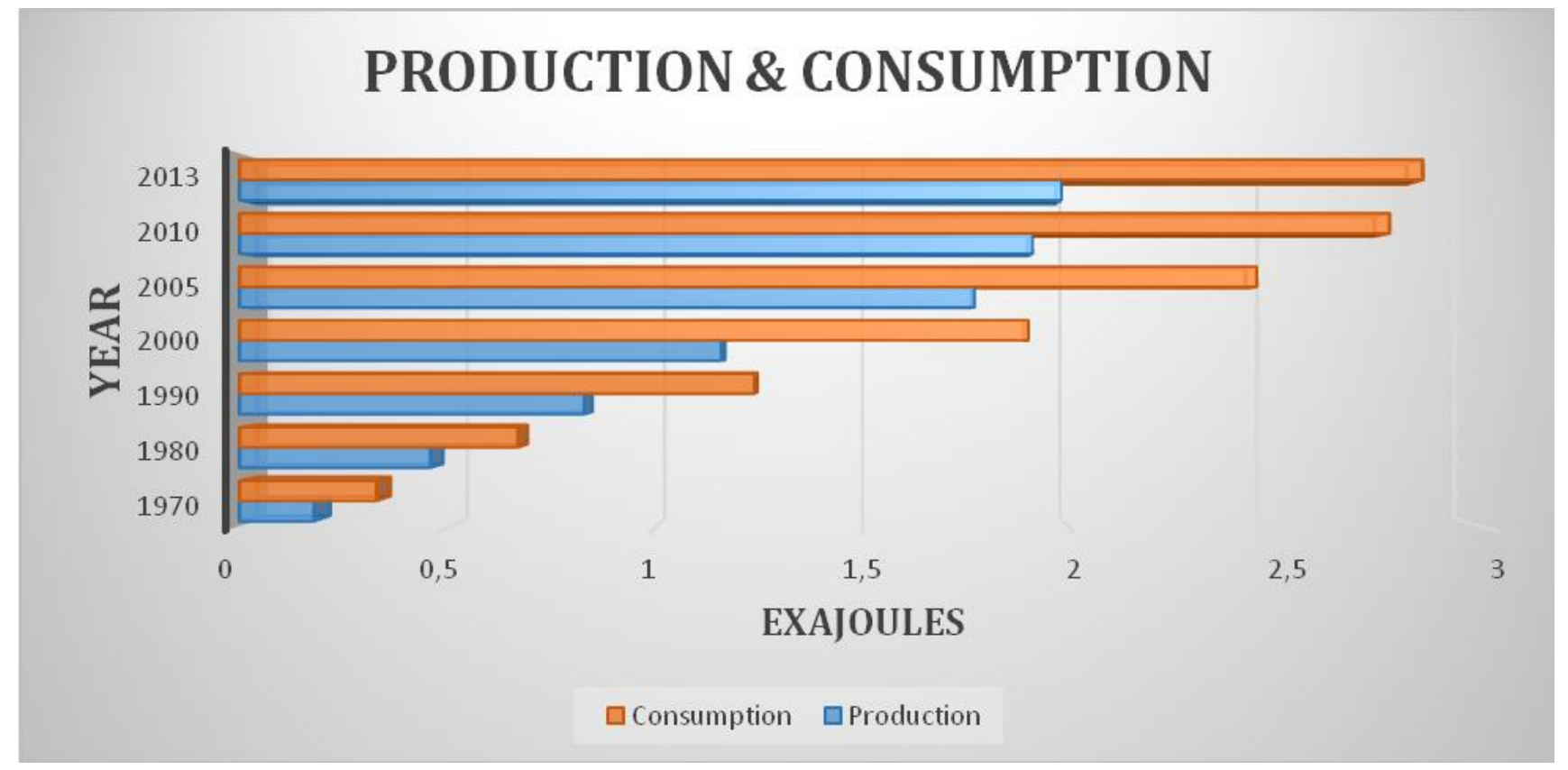

Figure 1. Graph of yearly energy consumption \& production [10] 


\section{Materials \& Methodology}

This study will present the necessity and methods of constructing energy-efficient buildings in hot regions like Pakistan. Climate data and geographical location of Pakistan is presented here. Mainly the data from the Building Energy Code of Pakistan and UN-Habitat Pakistan report is taken into account. This study indicates the importance of thermal improvement techniques in order to gain thermal comfort and energy efficiency. The benefits of the installation of renewable energy means (especially solar energy) are also highlighted since it is a cheap source of clean energy and it prevents the emission of greenhouse gases as well. The solar panels use has also been reinforced by software simulation. The main purpose is to encourage the construction of energy-efficient buildings to adopt a sustainable approach for infrastructure development.

A survey is also carried out inquiring people about their experiences related to cooling and heating in the buildings and their inclination towards thermal comfort and energy efficient buildings.

\section{Nearly Zero Energy Buildings (NZEBs)}

Nearly zero-energy buildings (NZEBs) are the buildings that have very high energy performance and efficiency. These buildings have really less energy demand and this demand is met by renewable energy source/s [11]. These buildings are the main focus of research in developed countries and extensive research has been made in this field. Different countries have come forward and contributed their share in this research. In the European Union, countries have set their goals to achieve nearly zero energy performance. EU has taken the initiative and set up a new directive "Energy Performance of Buildings Directive (EPBD)" which looks after the progress and identifies the improvement steps in reaching this high energy performance. EPBD requires all new buildings in the member states of EU to be nearly zero-energy by the end of 2020 [5].

These high-performance buildings mainly involve the installation of renewable sources of energy and high-performance equipment such as boilers, ventilation systems, etc. [5]. The energy demand of these building is really minimum and this energy demand can be fulfilled by renewable sources [7].

These nearly zero energy buildings are sustainable as well as environment-friendly since energy consumption is less so are the greenhouse gas emissions. One of the prominent advantages is costeffectiveness because if the energy demand of a building is less and it is met by renewable sources then the utility bills are going to be negligible. These high-performance buildings are not only saving the environment but also the expenditures of the owner in terms of utility bills [12]. NZEBs are discussed to reinforce the necessity of energy efficient buildings in Pakistan.

\section{Study Area-Pakistan}

The geographical location of Pakistan is approximately between $24-37^{\circ} \mathrm{N}$ latitude and $62-75^{\circ} \mathrm{E}$ longitude in the western zone of South Asia. Pakistan has a long summer period starting from the last days of March which finishes in September. The range of temperature in Pakistan is from $-20^{\circ} \mathrm{C}$ to $50^{\circ} \mathrm{C}$. So it is clear that Pakistan has both extreme scenarios in terms of low and high temperatures. 
The north region of Pakistan has mountain regions and it is colder than other parts of the country [13] [14] [15] [16].

Pakistan is more possessed with a hot climate than a cold climate. The lowest sunshine hours in Pakistan are recorded in January when the sun shines for 6.1 hours/day along with low rainfall and humidity and the longest duration of sunshine is recorded in July when the sun shines for 9.7 hours/day with high temperature and low humidity. It means that Pakistan receives a significant amount of solar energy throughout the year. This energy will compensate the electrical energy requirements of a building and reducing the load on the national/local grid. It will be a source of clean energy and cost-effective for the occupants in terms of low utility bills as well [17] [18].

\subsection{Building Energy Code in Pakistan:}

A sub-department of the Planning \& Development Division of Govt. of Pakistan, The National Energy Conservation Centre, has prepared a building energy code for energy efficient buildings in Pakistan in May 1990 after the energy crisis in 1970 to optimize energy consumption of buildings in Pakistan. Since buildings in Pakistan consume more than $40 \%$ of the total electric energy produced and this demand is increasing by $14 \%$ per annum. This code specifies the minimum energy conservation requirements for buildings envelope and are applicable to all types of buildings like residential houses/buildings, school buildings, hospitals, shops, and banks, etc. The requirements are set on the basis of zones as cities of Pakistan have been divided into 5 different zones and every zone has a different requirement. The map representing the above zones is also attached in the following figure:

\section{Climate Zones of Pakistan}

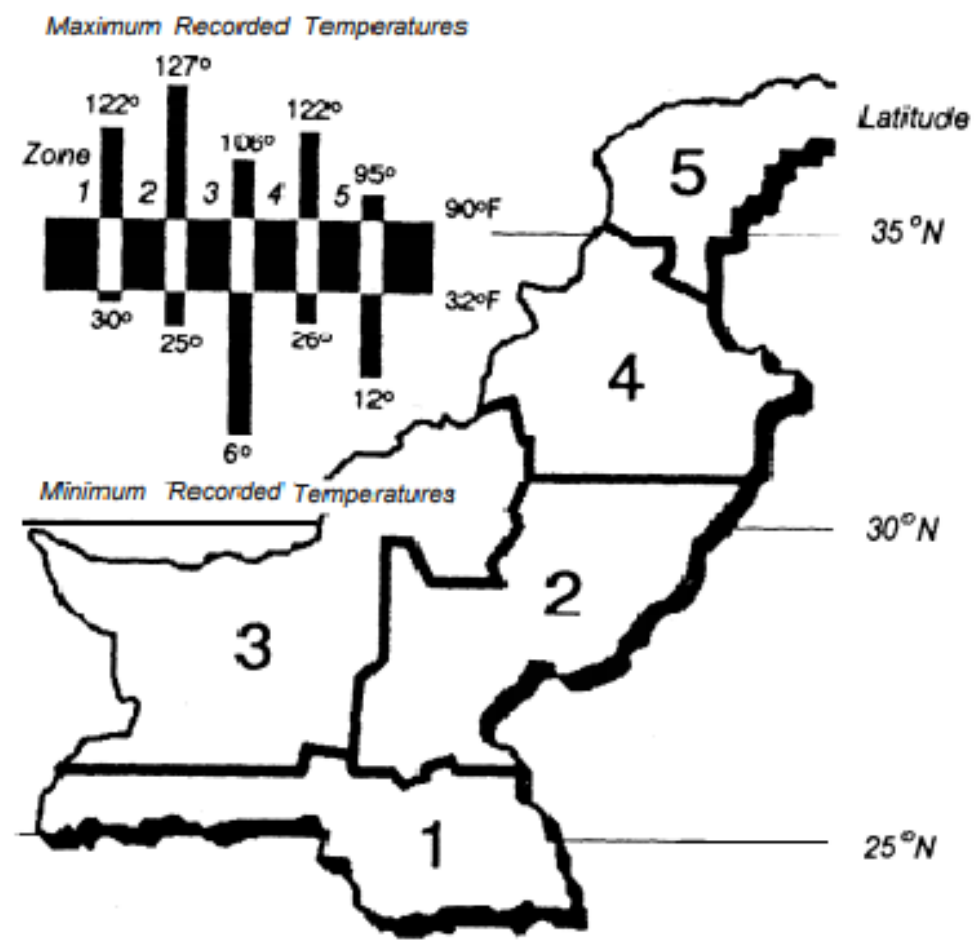

Figure 2. Zonal Map of Pakistan [19] 
The requirements for every component of building envelope have been provided according to the above-mentioned energy zones and these are presented hereunder:

\subsubsection{Roofs:}

In Pakistan, it is an uncommon tradition to construct multi-story flats or residential apartments. Most of the residential dwellings are one or two-story houses. According to the building energy code of Pakistan, the maximum values of heat transmission coefficient (Uo) for roofs and ceilings for all 5 zones are given below [19]:

\begin{tabular}{|c|c|c|c|c|c|c|c|}
\hline \multirow{2}{*}{ Element } & \multirow{2}{*}{ Criteria } & \multirow{2}{*}{ Unit } & \multicolumn{5}{|c|}{ Value } \\
\hline & & & Zone 1 & Zone 2 & Zone 3 & Zone 4 & Zone 5 \\
\hline Roof & $\begin{array}{c}\text { Heat Transmission Coefficient } \\
\text { (Uo) }\end{array}$ & $\mathrm{W} / \mathrm{sq} \cdot \mathrm{m}^{\circ} \mathrm{C}$ & 0.58 & 0.58 & 0.58 & 0.58 & 0.58 \\
\hline
\end{tabular}

Table 1. Maximum Uo values for Roofs for all 5 zones

\subsubsection{Walls:}

Walls of any building are also very susceptible to unwanted heat losses or gains because they are in contact with the outer atmosphere as well therefore much care is needed while constructing them and maximum heat transmission coefficient (Uo) limit should be kept in mind. The maximum values for walls in all zones of Pakistan are presented in the following table:

\begin{tabular}{|c|c|c|c|c|c|c|c|}
\hline \multirow{2}{*}{ Element } & \multirow{2}{*}{ Criteria } & \multirow{2}{*}{ Unit } & \multicolumn{5}{|c|}{ Value } \\
\hline & & & Zone 1 & Zone 2 & Zone 3 & Zone 4 & Zone 5 \\
\hline Walls & $\begin{array}{c}\text { Heat Transmission Coefficient } \\
\text { (Uo) }\end{array}$ & $\mathrm{W} / \mathrm{sq} \cdot \mathrm{m}^{\circ} \mathrm{C}$ & 2.67 & 2.56 & 2.22 & 2.5 & 2.22 \\
\hline
\end{tabular}

Table 2. Maximum Uo values for Walls for all 5 zones

It shows that the allowance for Uo is higher for walls than for roofs. A study also suggests that roofs usually have more heat resistance than walls and windows [20]. The thermal resistance is the reciprocal of heat transmission coefficient.

\subsubsection{Ventilation}

In Pakistan, using mechanical or artificial ventilation is not in common practice, therefore, natural ventilation should be properly provided by designing windows according to the wind's prevailing direction and suitable design of opposite walls.

The minimum area for windows that needs to be openable is the following percentage of the areas presented in table 3. Also, table 3 must be interpreted with the combination of table 4 . The table for minimum window area for natural ventilation given in Building Energy Code of Pakistan is given below [21]: 
International Journal of Engineering and Management Sciences (IJEMS) Vol. 4. (2019). No. 4

DOI: 10.21791/IJEMS.2019.4.12.

\begin{tabular}{|l|c|}
\hline \multicolumn{1}{|c|}{ Building Component } & Percentage \\
\hline Residential (Bedrooms, Drawing rooms, Dining rooms, Kitchens) & $50 \%$ \\
\hline Water Closet, Toilet, Bathroom, Laundry, etc. & $100 \%$ \\
\hline Stairs, Utility & $50 \%$ \\
\hline Corridor, Stair etc. & $50 \%$ \\
\hline
\end{tabular}

Table 3. Minimum openable areas of the window

The minimum area mentioned in the above table is actually the percentage of the total windows' area for different building components given in the following table. The table given below represents the minimum glass area for windows that is necessary for different building components. Table 3 must be taken into consideration in conjunction with table 4.

\begin{tabular}{|c|c|c|}
\hline \multirow[b]{2}{*}{ Building Component } & \multicolumn{2}{|c|}{ Unobstructed Glass Area } \\
\hline & $\begin{array}{l}\text { With No Electric } \\
\text { Lighting }\end{array}$ & With Electric Lighting \\
\hline $\begin{array}{l}\text { Laundry Basement, Unfinished Basement or } \\
\text { Cellar }\end{array}$ & $4 \%$ of the area served & Windows not required \\
\hline Water Closet Room & 0.37 sq.m & 0.37 sq.m \\
\hline Kitchen, Kitchen Space & $\begin{array}{l}10-15 \% \text { of the area } \\
\text { served }\end{array}$ & $\begin{array}{l}10-15 \% \text { of the area } \\
\text { served }\end{array}$ \\
\hline Living Rooms \& Dining Rooms & $\begin{array}{l}15-20 \% \text { of the area } \\
\text { served }\end{array}$ & $\begin{array}{l}15-20 \% \text { of the area } \\
\text { served }\end{array}$ \\
\hline $\begin{array}{l}\text { Bedroom, other rooms including bathroom } \\
\text { not mentioned above }\end{array}$ & $\begin{array}{l}10-15 \% \text { of the area } \\
\text { served with at least one } \\
\text { window }\end{array}$ & $\begin{array}{l}10-15 \% \text { of the area } \\
\text { served with at least one } \\
\text { window }\end{array}$ \\
\hline
\end{tabular}

Table 4. Minimum Glass Area for Rooms of Residential Occupancy

\subsection{Thermal Comfort and Occupants Behavior}

A survey was carried out to get information about the experiences of the thermal comfort in the buildings of the local residents. It is also important to note that the energy efficiency of a building is closely related to the thermal comfort of its occupants. For that purpose this survey was conducted to figure out the extent of thermal comfort by the occupants. The questions were asked to determine if the residents need some kind of air conditioners or heating to achieve a comfortable indoor temperature.

A question related to the development of the area of their building was also asked to gather information about the design of that area. The registered responses were 60. The people who participated in this survey were from different areas and the categories are divided as follows:

\begin{tabular}{|c|c|}
\hline Area & Percentage \\
\hline Well Planned like DHA/EME & $16.7 \%$ \\
\hline Irregular/Random design & $36.5 \%$ \\
\hline Moderately planned & $45 \%$ \\
\hline Other Areas & $1.8 \%$ \\
\hline
\end{tabular}

Table 5. Respondents' areas 
The above data shows that most of the people live in moderately planned areas. It refers to the areas which are designed to some extent under some supervision, however, still most of the houses in these areas are constructed without any check and balance by typical masons. Randomly planned areas are those where construction does not comply with any standard such as height, geometry, covered area, etc. Well planned areas are referred to those housing schemes which are built under proper supervision, everything is regulated and standardized. These schemes are constructed mostly in the outskirts of big cities to provide a comfortable, serene and quality experience of the housing.

The questions were asked to the dwellers about their urge to turn on artificial cooling during a summer day and night and their responses are recorded.

Similarly, questions about turning on artificial heating were also asked during a winter day and night. Data collected in the survey has been refined and rearranged according to the areas people are living in. A table of the data is formed regarding artificial cooling during day and night and it gives us an idea about how people feel about thermal comfort in different areas during summer.

\begin{tabular}{|c|c|c|c|c|c|c|c|c|}
\hline \multirow{2}{*}{ Area } & \multicolumn{4}{|c|}{$\begin{array}{c}\text { Do you feel the need to turn AC on } \\
\text { in summer during the day? }\end{array}$} & \multicolumn{2}{c|}{$\begin{array}{c}\text { Do you feel the need to turn AC on in } \\
\text { summer during the night? }\end{array}$} \\
\cline { 2 - 11 } & \multicolumn{2}{|c|}{ No } & \multicolumn{2}{|c|}{ Yes } & \multicolumn{3}{c|}{ No } & \multicolumn{3}{c|}{ Yes } \\
\hline $\begin{array}{c}\text { Moderately } \\
\text { planned }\end{array}$ & 3 & $11 \%$ & 24 & $89 \%$ & 6 & $22 \%$ & 21 & $78 \%$ \\
\hline $\begin{array}{c}\text { Random/without } \\
\text { any proper design }\end{array}$ & 4 & $18 \%$ & 18 & $82 \%$ & 4 & $18 \%$ & 18 & $82 \%$ \\
\hline $\begin{array}{c}\text { Well planned like } \\
\text { DHA/EME }\end{array}$ & 3 & $30 \%$ & 7 & $70 \%$ & 3 & $30 \%$ & 7 & $70 \%$ \\
\hline Other areas & 0 & $0 \%$ & 1 & $100 \%$ & 0 & $0 \%$ & 1 & $100 \%$ \\
\hline
\end{tabular}

Table 6. Area-wise data on artificial cooling during summer

The above data depicts that the hot climate is so dominant that the occupants hardly feel any difference in temperature during day and night even though the temperature falls as the sun goes down. It clearly indicates that during the day, components of houses like the floor, wall, etc. absorb heat and during the night, this absorbed heat is released and the residents feel the urge to turn on the cooling. It clearly manifests that the construction of houses in Pakistan is done without considering the factors of heat transfer, and heat storage capacity. If the heat is prevented from entering the building during day from outdoor environment, then there might be very low need of cooling and the cooling will be effective as there is no heat flowing indoor to counter the cooling and heat absorption in components of buildings also need to be avoided to prevent its release during night when temperature is generally lower [22]. If no heat is absorbed and released, there will be a minimum need for artificial cooling at least during the night.

Now, the data for mechanical heating in winter during day and night is analyzed and presented in a table below: 


\begin{tabular}{|c|c|c|c|c|c|c|c|c|}
\hline \multirow{2}{*}{ Area } & \multicolumn{2}{|c|}{$\begin{array}{c}\text { Do you feel need to turn heating on } \\
\text { in winter during the day? }\end{array}$} & \multicolumn{2}{c|}{$\begin{array}{c}\text { Do you feel need to turn heating on in } \\
\text { winter during the night? }\end{array}$} \\
\cline { 2 - 10 } & \multicolumn{2}{|c|}{ No } & \multicolumn{2}{|c|}{ Yes } & \multicolumn{3}{c|}{ No } & \multicolumn{2}{c|}{ Yes } \\
\hline $\begin{array}{c}\text { Moderately } \\
\text { planned }\end{array}$ & 16 & $59 \%$ & 11 & $41 \%$ & 4 & $15 \%$ & 23 & $85 \%$ \\
\hline $\begin{array}{c}\text { Random/without } \\
\text { any proper design }\end{array}$ & 15 & $68 \%$ & 7 & $32 \%$ & 6 & $27 \%$ & 16 & $73 \%$ \\
\hline $\begin{array}{c}\text { Well planned like } \\
\text { DHA/EME }\end{array}$ & 2 & $20 \%$ & 8 & $80 \%$ & 2 & $20 \%$ & 8 & $80 \%$ \\
\hline Other areas & 1 & $100 \%$ & 0 & $0 \%$ & 0 & $0 \%$ & 1 & $100 \%$ \\
\hline
\end{tabular}

Table 7. Area wise data on mechanical heating during winter

In this table, a trend is clear that in moderately and random planned areas people do not feel the need for artificial heating during the day but at night most of them do not feel comfortable and they want to turn on the heating. It is also linked to the fact that temperature during night decreases generally. Therefore, when the outdoor temperature decreases, indoor heat starts flowing towards the outer environment and this leakage of heat causes the low temperature in the indoor environment as well making people uncomfortable to the point of turning on artificial heating.

\section{Potential Measures:}

It is really necessary to take important measures in disseminating the importance of energy efficient buildings in Pakistan. Pakistan is badly affected by global warming and it is a common observation that every year temperature in summer is more than the previous year. The energy crisis in Pakistan is also a reason why Pakistan should move towards nearly zero-energy buildings. Moreover, the prices of energy are skyrocketing as well making it difficult for the common middle-class people to manage their household expenses [23].

There are certain ways that can be adopted to improve the efficiency of buildings and bring them close to nearly zero-energy buildings.

\subsection{Thermal Improvement Techniques:}

UN-Habitat Pakistan has carried out extensive research on implementing thermal improvement techniques on the top surface of roof slabs [24]. Mostly residential buildings in Pakistan are 1 or 2 story buildings, therefore, the effect of heat gain warms up the whole building in summer leaving an uncomfortable level of temperature for the occupants.

UN-Habitat Pakistan carried out its practical research in the capital city, Islamabad, of Pakistan where the temperature usually crosses $40^{\circ} \mathrm{C}$ in summer. The techniques [24] which are found to be most useful in reducing the internal temperature up to $34^{\circ} \mathrm{C}$ without any artificial cooling are presented hereunder: 


\subsubsection{Insulative Techniques:}

Insulation plays an important role in preventing unwanted heat transfers as it does not allow heat to pass through it. In a well-insulated building, there are really fewer changes in the room temperature and thermal comfort is readily available. In a hot climate, a good insulation layer does not let outdoor heat enter the building and warm up the indoor environment to an uncomfortable level. Whereas, in a cold climate, this insulation prevents indoor heat from flowing to the outdoor environment eventually decreasing the inside temperature.

The insulative techniques applied on the roof surfaces by UN-Habitat reduced the heat conduction to a great level. These techniques are described below [24]:

1. Stabilized mud (Cement Stabilization)

2. Mud with high-density styrofoam (Thermo pole)

3. Brick tiles with stabilizing mud

4. Polystyrene (Jumbolon) with plain concrete screed

5. Concrete wizard insulating tiles

6. Sachal CLC (Cellular lightweight concrete) tiles

7. Smart concrete tiles (aerated concrete with thermo pole used as a sandwich between concrete layers)

8. Munawar AC tiles (Terrazzo mixed with epoxy with thermos pole sheet)

9. Fired clay extruded hollow tiles

10. Green Netting

\subsubsection{Reflective Techniques:}

If sunlight does not get absorbed in a material, the heat transfer will be very low. The reflective techniques are used to reflect sun rays to minimize the absorption of heat energy in the roof. It is also a well-known fact that a dark color absorbs more sunlight and a light color reflects most of the sunlight and absorbs really less heat energy. The reflective techniques employed by UN-Habitat Pakistan are presented below [24]:

1. Limewash

2. White Enamel paint

3. Weather shield white paint

4. OCEVA-MOL chemical

5. Aerosol Heat reflective paint

\subsubsection{Radiant Barrier Techniques (Suspended Ceiling):}

When there is no insulation/reflective material on the roof, all the heat energy absorbed by the roof slab will be transferred to the room below. Therefore, a barrier is required to stop this flow of heat energy. A radiant barrier is used for this purpose which an additional layer. Most of the time a suspended ceiling is used for this purpose and it is made up of some insulative or reflective material. A gap also exists between the original ceiling and suspended ceiling which traps the heat and the 
suspended ceiling does not let it pass. The radiant barrier techniques applied are given hereunder [24]:

1. Gypsum board suspended ceiling

2. Gypsum board with aluminum foil on the back

3. Paperboard suspended ceiling

4. Thermo pole suspended ceiling

\subsection{Data Collection by UN-Habitat Pakistan}

UN-Habitat Pakistan collected data during this practical research by comparing the temperature measurements of the improved houses with a control house with no improvements. This data showed considerable results for the various techniques. Data corresponding to temperature reduction for some of the techniques has been added in Fig. 3 [24]. It indicates that Extruded Polystyrene is the best material as insulation since it prevented heat transmission to a large extent.

\begin{tabular}{|c|c|c|c|}
\hline \multirow{4}{*}{ S/No. } & \multirow{2}{*}{ Solution } & \multicolumn{2}{|c|}{ Temperature } \\
\hline & & 3:00pm & 12:00am \\
\hline & Outside Temperature & 41.0 & 32.0 \\
\hline & Control house (no improvements) Inside temperature & 36.2 & 36.7 \\
\hline 1. & Stabilized mud & 35.3 & 35.4 \\
\hline 2. & Mud with thermo pole & 33.6 & 34.1 \\
\hline 3. & Brick tiles with stabilized mud & 33.1 & 33.9 \\
\hline 4. & Extruded Polystyrene (Jumbolon) & 32.2 & 32.0 \\
\hline 5. & Concrete wizard tiles & 34.7 & 35.6 \\
\hline 6. & Sachal CLC tiles & 34.0 & 34.0 \\
\hline 7. & Smart concrete tiles & 33.7 & 32.0 \\
\hline 8. & Munawar AC tiles & 33.0 & 33.4 \\
\hline 9. & Alnoor tile & 34.1 & 33.8 \\
\hline 10. & Green netting & 35.1 & 33.7 \\
\hline 11. & Lime wash & 33.1 & 32.6 \\
\hline 12. & Weather shield paint (white) & 33.7 & 32.6 \\
\hline 13. & White enamel paint & 33.1 & 32.9 \\
\hline 14. & Aerosol heat reflecting paint & 34.2 & 33.4 \\
\hline \multirow[t]{2}{*}{15.} & OCEVA-MOL chemical & 34.7 & 33.6 \\
\hline & Average & \multicolumn{2}{|c|}{ Very Good } \\
\hline
\end{tabular}

Figure 3: Temperature data compared with a control house [23]

The cost requirements for the installation of some of those techniques are also stated in the below picture. The 10-years cost shows the expenses incurred for the insulation in next 10 years. Insulation materials no. $14 \& 15$ need to be replaced every year therefore, the 10 -years cost is 10 times the first time installation cost. It also indicates that Extruded Polystyrene can be a better choice as insulation material. 
DOI: 10.21791/IJEMS.2019.4.12.

\begin{tabular}{|c|c|c|c|}
\hline No. & Solution & $\begin{array}{c}\text { Initial cost } \\
\text { Rate/ sft (PKR) }\end{array}$ & $\begin{array}{l}10 \text { years cost } \\
\text { Rate/ sft (PKR) }\end{array}$ \\
\hline 1. & Stabilized Mud & 32 & 32 \\
\hline 2. & Mud with thermo pole & 52 & 52 \\
\hline 3. & Brick tiles with stabilized mud & 39 & 39 \\
\hline 4. & Extruded polystyrene (Jumbolon) & 76 & 76 \\
\hline 5. & Concrete wizard tile & 78 & 78 \\
\hline 6. & Sachal CLC tiles & 80 & 80 \\
\hline 7. & Smart concrete tiles & 70 & 70 \\
\hline 8. & Munawar AC tiles & 80 & 80 \\
\hline 9. & Alnoor tiles & 81 & 81 \\
\hline 10. & Green netting & 60 & 60 \\
\hline 11. & Lime wash & 3 & 30 \\
\hline 12. & Weather shield paint & 8 & 80 \\
\hline 13. & White enamel paint & 8 & 80 \\
\hline 14. & Aerosol heat reflecting paint & 39 & 390 \\
\hline 15. & OCEVA-MOL chemical & 35 & 350 \\
\hline
\end{tabular}

Figure 4: Cost of different materials used for thermal improvement in square feet [24]

\subsection{Installation of Renewable Sources (Mainly Solar)}

Installing renewable sources on an energy efficient building to compensate the energy requirements brings the building close to nearly zero energy building. Now, in Pakistan, such kind of air conditioners have been developed that can run on solar energy. Pakistan receives a considerable amount of sunlight throughout the year and it has a lot of potentials to utilize this solar energy and decrease the load on the national grid. Solar panels can be installed on roofs to supply electricity to the house and this energy can also be stored during peak hours of sunlight if a storage system is employed as well [17].

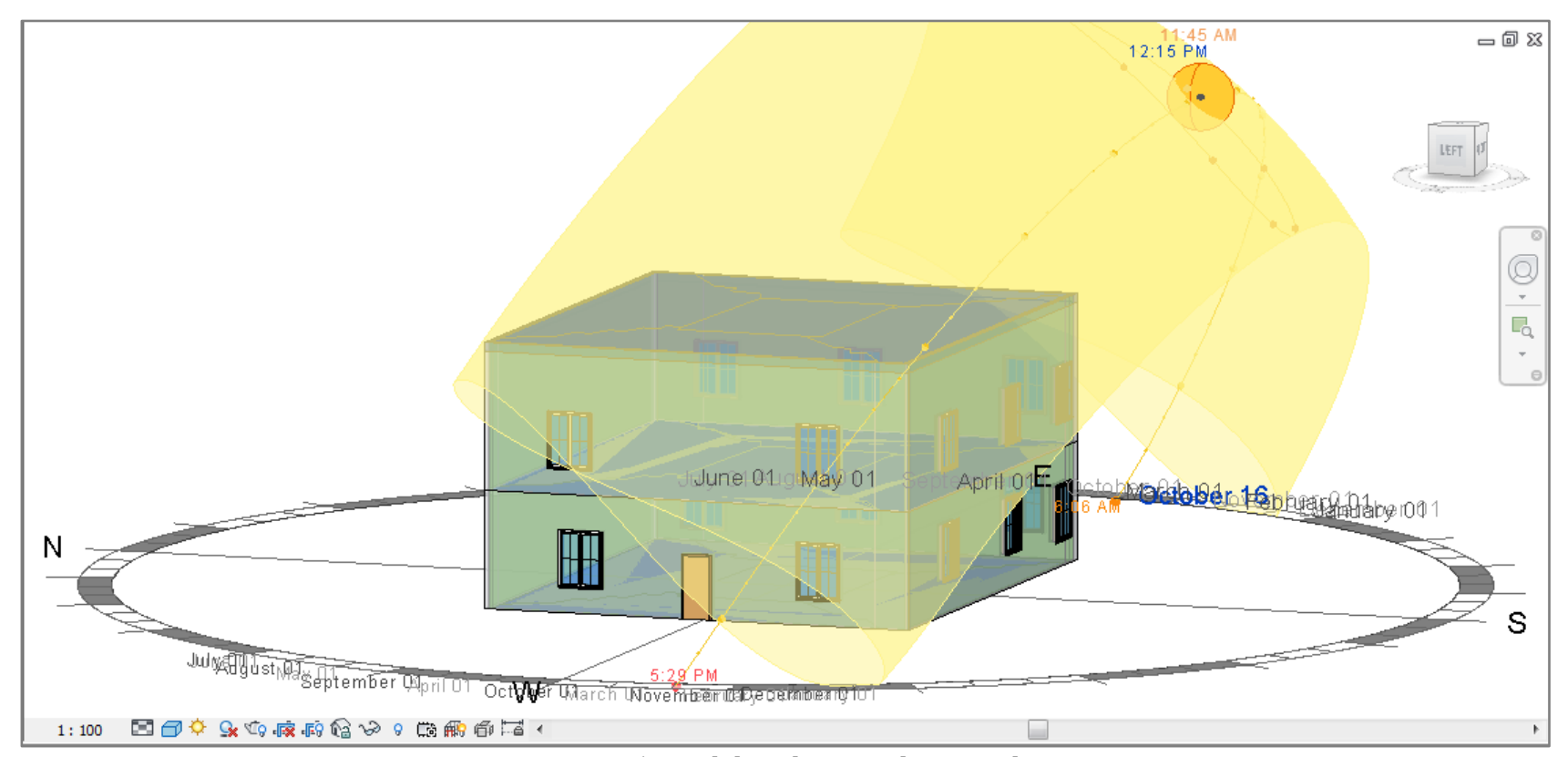

Figure 5: Model with annual sun path

A solar analysis is also carried out on a model created in Autodesk Revit to highlight the potential of solar power generation by installing solar panels/photovoltaic panels on the buildings. The analysis 
was carried out in a cloud-based engine "Revit Insight" of Autodesk. Autodesk Revit is one of the best software for Building Information Modeling (BIM) and energy analysis [25] [26]. A double-story 10 Marla house (approx. 252 sq. meter) is created in the software and then an energy model is generated. The houses with this area are common in Pakistan. This model is created with no insulations following the common practice in Pakistan of not using thermal insulation for preventing unwanted heat transmissions and heat loses. The main purpose is to analyze the potential of solar energy only at this stage. The location of the model is set to Gulberg, Lahore in Pakistan which is a relatively well-planned area and the nearest weather station is selected for the meteorological data. A picture has been attached from the model to manifest the sun path.

The sun path suggests that Pakistan has a huge potential of solar energy and it can produce solar energy all-round the year. Studies have also manifested that Pakistan has a significant scope of solar energy. The geographical location of Pakistan is the reason why many parts of Pakistan receive an enormous amount of sunlight. There are areas that receive $2 \mathrm{MWh} / \mathrm{sq} . \mathrm{m}$ year of solar radiation and the hours of sunshine are 3000/year. The scope for daily mean solar power is $5.3 \mathrm{kWh} / \mathrm{sq} . \mathrm{m}$ which is remarkable [27] [28] [29].

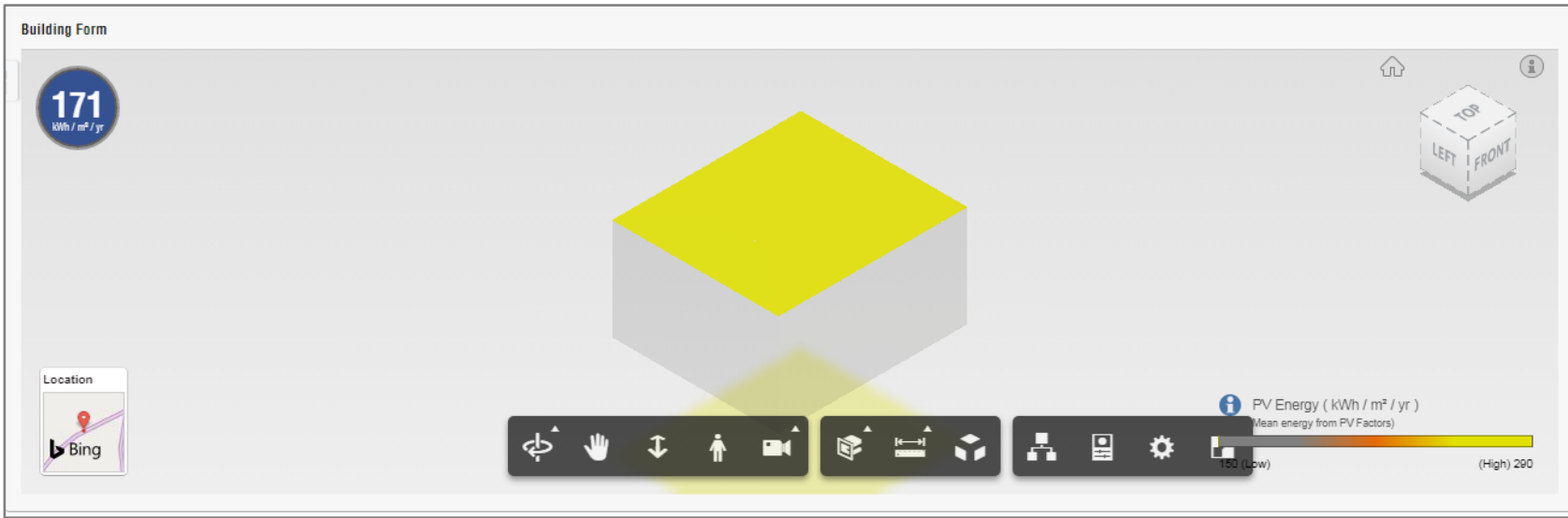

Figure 6. Potential location for PV installation on the roof

The Energy Use Intensity (EUI) has been analyzed using the Autodesk Revit Insight for both without solar panels and with solar panels to exhibit the potential of solar energy. Energy Use Intensity (EUI) is the energy use by a building which is calculated by dividing the total energy consumption per year in a building by its total gross floor area [30]. In this solar energy analysis, we have used EUI as the reference for the calculation of solar energy scope. The EUI without solar panels and after installing solar panels (60\% surface coverage area) has a significant difference. It actually has been reduced from $228 \mathrm{kWh} / \mathrm{sq}$. m per year to $171 \mathrm{kWh} / \mathrm{sq}$. m per year after placing solar panels in the model.

Revit Insight has a powerful tool to portray the places on the roof of a building to place solar panels. The potential is also highlighted to depict the locations where solar power potential is high and where it is low in order to provide a better idea as in Fig. 6. It shows that the whole roof can be covered with solar panels to generate prospective solar power. Also, the surrounding buildings need to be taken into account while analyzing the surface coverage since those buildings can pose shadows by hindering the sunlight, however, at this moment no such other building is considered posing shadows on our model. 
The comparison of scenarios with solar panels and without solar panels is also presented in the picture below:

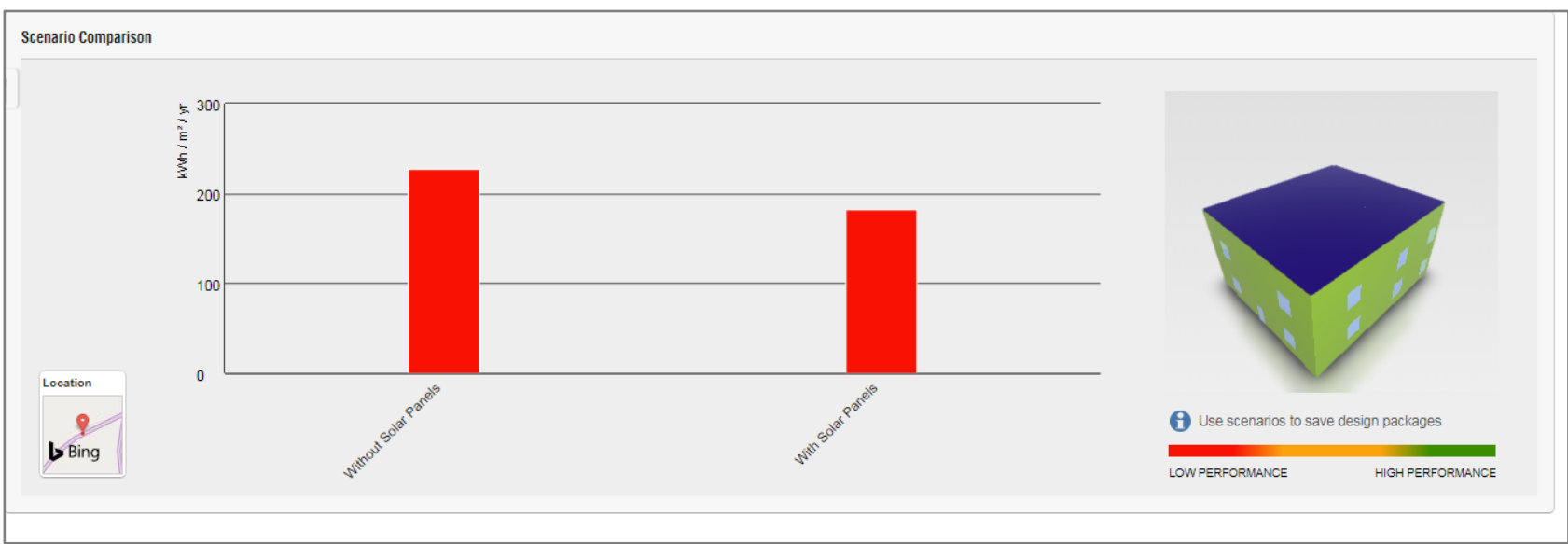

Figure 7. Scenario comparison

It indicates that $0 \%$ area coverage of the roof with solar panels has high energy use intensity of 228 $\mathrm{kWh} / \mathrm{sq} . \mathrm{m}$ per year. However, when the roof surface coverage is $60 \%$ then the Energy Use Intensity is $171 \mathrm{kWh} / \mathrm{sq} . \mathrm{m}$ per year which is considerably less. It exhibits that covering $60 \%$ of roof area with solar panels can reduce the EUI to a remarkable amount. If insulations and other thermal techniques are employed with the solar panels then the buildings can come closer to the stage where energy demand is very low and its own energy production is almost enough to meet that energy demands with consuming almost zero or negligible electricity from the grid. Since, electricity is the main concern in Pakistan due to the major electricity crisis in Pakistan, therefore, only the potential of electric power generation at this stage has been manifested by the installation of solar panels in this study.

Now a new trend of Building Integrated Photovoltaics (BIPV) is also revolutionizing solar energy production. These are solar panels to replace some materials/components of a building. These BIPV can be installed on roofs, walls, and sunshades. These integrated photovoltaics also help in reducing some of the cost spent on building components that are replaced by photovoltaic panels [31].

These renewable energy sources can lead a building to a net-zero energy building or even plus energy stage as this concept involves turning a building into small powerhouse by extensive use of roof solar panels. However, these buildings can only be independent in terms of self-sufficiency when the building has really less energy demand [7].

\section{Discussion and Recommendations}

Humans cannot survive forever on energy generated by utilizing fossil fuels as these energy sources are diminishing really fast and causing global warming as well. Sustainable energy sources are needed to be adopted by humans more extensively. However, attention is also required towards reducing overall energy needs as well since energy demand is increasing drastically with every passing year. United Nations (UN) has also given stress on this factor and included it in its list of sustainable 
development goals. It is direly required to point out the potential areas where energy consumption can be reduced and conventional energy consumption can be replaced with green energy production.

Pakistan has a significant potential for solar power along with wind energy and it should be utilized on an urgent basis. The government of Pakistan also needs to play its part in optimizing the energy consumption in the country which eventually affects the energy consumed in the whole world. Pakistan also comes in the list of those countries which are affected badly due to global warming and concrete actions are required to be taken to prevent the global warming effect. Since a large portion of the energy produced is consumed by buildings in Pakistan as well, therefore, this sector needs immediate action. The whole discussion above presented many different solutions for making buildings more efficient and benefits of energy efficient buildings. Pakistan also has energy efficient building codes but these are not given enough importance while constructing new buildings and retrofitting old buildings. Some suggestions to be implemented are provided below:

- A department needs to be assigned this responsibility to make sure that these energy codes and guidelines are being employed in buildings.

- Criteria for energy efficiency should be devised as a baseline to measure energy efficiency according to this criteria.

- A certification system should be developed like Energy Performance of Building Directive (EPBD) has developed and implemented in their member states by properly monitoring and testing building energy efficiency. This certification system will increase the awareness, need and worth of energy efficient

- A list of goals and objectives should be developed by the concerned department about making a particular number of buildings energy efficient up to a specific year just like EPBD is trying to make every building, nearly zero-energy by the end of 2020 .

- Incentives should be granted to those in terms of discounts on utility bills that implement energyefficient solutions in their dwellings.

- An awareness campaign should be initiated in order to make people aware of the importance, benefits, and sustainability of energy-efficient buildings.

- Subsidies should be provided on materials that are used to enhance the energy efficiency of buildings.

- Tax should not be charged on imported equipment for utilizing renewable energy by the government.

- Energy audits should be carried out for analyzing the energy consumption within a building/system to find out energy flows and suitable potential areas for improvement.

- Monitoring reports should be developed every 3-5 years in order to go through the whole progress in the last years and devise methods for further improvement.

\section{References}

[1] L. Neij, H. Bulkeley and. K. McCormick, "Cities and climate change: The great decarbonisation challenge," Climate in Focus, pp. 1-4, 2015.

[2] WWF, "REINVENTING THE CITY: THREE PREREQUISITES FOR GREENING URBAN INFRASTRUCTURES," www.panda.org, 2010. 
[3] “Energy Technology Perspective 2017," International Energy Agency (IEA), 2017.

[4] I. OCED, "Green Growth Studies: Energy," OCED Publishing, 2011.

[5] M. Klinski and S. Geissler, "Implementing the energy Performance of Building Directive (EPBD)," Concreted Action Energy Performance of Buildings CA EPBD, June 2013.

[6] Gandhi Habash, D. Chapotchkine, P. Fisher and . A. Rancourt, "Sustainable Design of a Nearly Zero Energy Building," Journal of Renewable Energy, p. 11, 2014.

[7] S. Mekjian, Ed., Active For More Comfort: Passive House, 2nd ed., International Passive House Association Germany, 2014.

[8] A. Hasan and H. Arif, "Pakistan: the causes and repercussions of the housing crisis," International Institute for Environment and Development (IIED), 2018.

[9] A. Malik, Power Crisis in Pakistan: A Crisis in Governance?, Pakistan Institute of Development Economics, 2012.

[10] “Country Nuclear Power Profiles," International Atomic Energy Agency, 2016.

[11] K. E. Thomsen, J. Rose and S. O. Ag, "Principles for nearly Zero-Energy Buildings," Buildings Performance Institute Europe (BPIE), 2011.

[12] G. Paoletti, R. Pascual Pascuas, R. Pernetti, and. R., "Nearly Zero Energy Buildings: An Overview of the Main Construction Features across Europe," buildings-Multidisciplinary Digital Publishing Institute, 2017.

[13] M. Qasim, S. Khalid and D. F. Shams, "Spatiotemporal Variations and Trends in Minimum and Maximum Temperatures of Pakistan," Journal of Applied Environmental and Biological Sciences, 2014.

[14] Z. A. Siddiqui, "Seasonal Forecasting at Pakistan Meteorological Department," Pakistan Meteorological Department, 2016.

[15] Anglia, "Average Monthly Temperature for Pakistan from 1991-2015," Climate Change Knowledge Portal, 2016.

[16] G. Qaiser, “Climate of Pakistan in 2017," National Drought Monitoring Centre (NDMC), 2017.

[17] S. Khan, M.-U.-H. and M. A. Khan, "Annual and Seasonal Distribution of Sunshine in Pakistan 19311990," in Water resources and wetlands, Tulcea, 2012.

[18] J. Grove-Smith, "How Passive House helps with delivery of NZEBs," in UK Passivehaus Conference, 2014.

[19] Building Energy Code of Pakistan, Ministry of Housing \& Works, Pakistan, 1990.

[20] K. A. B. Timothy L Hemsath, "Building Design with Energy Performance as Primary Agent," in 6th International Building Physics Conference, IBPC, 2015.

[21] The Code Compliance Handbook, National Energy Conversation Center (ENERCON), 1990.

[22] N. B. Geetha and R. Velraj, "Passive cooling methods for energy efficient buildings with and without thermal energy storage - A review," Energy Education Science and Technology Part A: Energy Science and Research, vol. 29, no. 2, pp. 913-946, 2012.

[23] M. Hancock, "Improving Thermal Comfort By Passive Thermal Design: A Study Of The Effectiveness And Practical Application Of A Range Of Strategies In Primary Schools In Pakistan," School of Architecture, Oxford Brookes University, 1999.

[24] "Energy Efficient Housing-Improvement of Thermal Performance of RC Slab Roofs," United Nations Pakistan (UN-Habitat Pakistan), 2010. 
[25] J. Chang, “Best 20 Building Information Modeling (BIM) Software in 2019," 2019. [Online]. Available: https://financesonline.com/building-information-modeling/.

[26] R. Bouška, "Evaluation of maturity of BIM tools across different software Platforms," in Creative Construction Conference 2016, Prague, 2016.

[27] M. Irfan, Z.-Y. Zhao, M. Ahmad, and M. C. Mukeshima, "Solar Energy Development in Pakistan: Barriers and Policy Recommendations," Sustainability 2019, 11, 1206, 2019.

[28] L. Jatoi, "Policy for Development of Renewable Energy for Power Generation: Government of Pakistan; Alternative," 2006.

[29] M. Iftikhar, F. Najeeb, S. Mohazzam and S. Khan, "Sustainable Energy for All in South Asia Potential, Challenges, and Solutions," Working Papers id:12275, eSocialSciences, 2017.

[30] J.-H. C. Chao Yanga, "Energy Use Intensity Estimation Method Based on Façade Features," in International Conference on Sustainable Design, Engineering and Construction, 2015.

[31] A. G. AboKhalil and D. S. S. Ahmed, "A New Approach to Improve the Energy Efficiency of MiddleEast Buildings," in Future of Renewable and New Energy in the Arab World, Assiut, 2013. 